\title{
PROCESSOS, FORMAS E INTERAÇÕES ESPACIAIS
}

\author{
Roberto Lobato Corrêa \\ Universidade Federal do Rio de Janeiro \& \\ Universidade do Estado do Rio de Janeiro
}

\begin{abstract}
Resumo
Este pequeno ensaio visa contribuir para a Geografia discutindo três pontos centrais: processos, formas e interações espaciais. Por meio deles estabelece-se a organização do espaço e sua dinâmica, o objeto principal do estudo geográfico. Concentração e dispersão são os processos espaciais mais gerais, que resultam em centros e periferias, lugares centrais e áreas especializadas, em condomínios exclusivos e favelas, em áreas fabris distintas e habitat rural disperso. As relações entre processos e formas, no entanto são complexas. Os processos, isto é, tempo e movimento, afetam as formas, isto é, a pausa e o espaço, mas o espaço pode 'congelar' o tempo. A refuncionalização de formas antigas é o melhor exemplo. Convergência, divergência e intercausalidade entre processo e forma são aspectos vinculados a esta complexidade. As interações espaciais cumprem o papel de articulação entre as formas espaciais. São também complexas e se distinguem segundo a natureza, velocidade, intensidade, frequência e direção. As redes geográficas constituem o arranjo espacial das interações, sendo constituídas por pontos e linhas (via de regra cidades, vias e fluxos).
\end{abstract}

Palavras-chave: organização espacial; processos; formas; interações.

\begin{abstract}
This brief essay aims to discuss three central points: spatial processes, forms and interactions. Together, these may be said to constitute the core of geographical enquiry, i.e., the spatial organization and dynamics of human society. Concentration and dispersion are the most general spatial processes, which lead to centers and peripheries, central places and specialized areas, exclusive condominiums and slums, industrial districts and rural disperse habitat. However, the relationships between processes and forms are complex. Processes (i.e., time and movement) affect forms (i.e., pause and space), but space can 'freeze' time. Refunctionalization of old forms is the best example. Convergence, divergence and intercausality between process and form are all related to this complexity. Spatial interactions play the role of articulating forms. They are also complex and distinguish themselves according to their nature, speed, intensity, frequency and direction. Geographic networks constitute the spatial arrangement of interactions, comprising nodes and lines (as a rule, urban centers, routes and flows).
\end{abstract}

Key words: spatial organization; processes; forms; interactions.

ste ensaio visa ressaltar alguns pontos essenciais da Geografia. Estes pontos, entre outros, estão entre aqueles que balizam a pesquisa geográfica, fornecendo à Geografia a sua identidade. EEles não são exclusivos desta ciência, mas nela adquirem grande centralidade. Identidade e centralidade de/em um campo de conhecimento que tem na espacialidade humana o seu modo de olhar a realidade.

A ação humana sobre a superfície terrestre ampliou as diferenças espaciais criadas pela Natureza, tornando a superfície terrestre mais complexa, diferenciada. Estabelece-se a espacialidade humana, que tem na diferenciação e integração de áreas a sua definição mais geral. Reflexo, meio e condição social, a espacialidade humana resulta de processos espaciais, criadores de 
formas e interações espaciais. As relações entre eles são muito complexas e este ensaio procura encaminhar algumas interpretações sobre cada um e sobre as relações entre eles.

\section{Concentração e dispersão espaciais}

Os processos espaciais criados pela ação humana geram dois arranjos espaciais fundamentais de formas espaciais: concentração e dispersão. Esta distinção, no entanto, deve ser relativizada em razão da escala de observação do pesquisador. As mesmas formas espaciais podem parecer concentradas em uma dada escala, digamos 1:1.000.000, e dispersada em outra escala, digamos, 1:10.000.

\section{A concentração espacial}

A concentração espacial resulta das forças de atração, como denominado por Colby, na década de 1930, ou forças de coesão ou ainda em função de economias externas de aglomeração. Tanto a ocorrência de recursos naturais em certas áreas quanto a localização de um grupo cultural em pequena área podem atrair determinados objetos ou gerar uma concentração de um grupo cultural. Estas áreas de concentração estão inscritas na divisão territorial do trabalho ou em um mosaico de regiões culturais ou naturais. Região, zona, área e distrito são termos que designam esta concentração, enquanto termos como core, periferia, franja e limite designam seções no interior de uma área de concentração.

$\mathrm{Na}$ escala regional ou nacional, a concentração está presente em regiões agrícolas caracterizadas por um produto dominante ou uma combinação de produtos: zonas do café, cacau, trigo ou de frutas são exemplos dessas concentrações. As regiões industriais e culturais constituem outros exemplos de concentrações espaciais. As primeiras concentram um ou dois gêneros da indústria - ou inúmeros gêneros, via de regra com interdependência entre eles. A região cultural, por sua vez, concentra um grupo etnolinguístico ou religioso que a distingue de outras regiões culturais, distinção que comumente se faz também pela paisagem cultural própria.

$\mathrm{Na}$ escala intraurbana, a concentração espacial manifesta-se na área central, particularmente no núcleo central, onde tradicionalmente verifica-se a máxima concentração de atividades do setor terciário. Esta concentração é considerada como centralização, um caso particular de concentração na área central da cidade. O distrito especializado, industrial ou de serviços, constitui outra forma resultante do processo de concentração, assim como o shopping center, forma moderna, criada na década de 1950, e resultado da ação planejada de capitais que perceberam a importância da concentração e a transformaram em investimentos de alta taxa de lucro.

A concentração espacial está presente também nas áreas sociais, formas espaciais resultantes do processo de segregação residencial. As áreas sociais fragmentam o espaço urbano, 
estabelecendo um mosaico irregular, no qual as distinções entre áreas de devem às diferenças em termos de status social, ocupação, qualidade da habitação e outros atributos como estrutura familiar, migração, etnia e religião. É o resultado, em última análise, do diferencial de acesso à terra e à moradia, transformadas em mercadorias particulares. As diferenças entre áreas sociais se fazem em termos de classes sociais e suas frações.

As áreas sociais aparecem sob diversas formas espaciais. Áreas de condomínios exclusivos, que concentram população de alto status e áreas de favelas, onde vivem populações de baixo status social. São os extremos sociais em sua espacialidade. Entre os extremos situam-se bairros de classe média, diferenciados segundo diversas frações, e que aparecem sob forma verticalizada ou de habitações unifamiliares, as áreas de cortiços, deteriorada e objeto de intervenções, sendo revalorizadas, conjuntos habitacionais e áreas de autoconstrução, de natureza popular e localizadas nas periferias urbanas.

Pode-se falar, em realidade, em um espaço econômico e em um espaço social, ambos resultantes do processo de concentração que cria diferenças econômicas e sociais que são uma das bases de interesse para a pesquisa geográfica. Descrever e tornar inteligível estas concentrações espaciais é tarefa fundamental do geógrafo.

\section{A dispersão espacial}

A organização espacial resulta também de processos que geram dispersão de formas espaciais, ainda que seja necessário relativizar a distinção entre concentração e dispersão, como já comentado anteriormente. O processo de dispersão tem suas bases no fato de que certos objetos têm mais eficiência na realização de suas funções por meio da dispersão, enquanto outros convivem bem tanto de modo concentrado como disperso. Isto relativiza de nova as diferenças entre concentração e dispersão.

O processo de dispersão tem duas origens. De um lado resulta da difusão de objetos a partir de um ou mais focos iniciais. De outro, resulta do aparecimento 'in sito' e de modo independente, de objetos. Ambos os modos de gênese têm importância para a organização espacial, mas é de se admitir que o primeiro modo adquira, em um mundo globalizado, importância progressivamente maior a partir da formação e expansão de redes vinculadas às grandes corporações e mesmo a empresas menores.

A dispersão oriunda da difusão projeta, para além dos focos iniciais - 'hearth' na linguagem dos geógrafos culturais - repetições locacionais de características semelhantes, embora não exatamente iguais, de características existentes nos focos iniciais. A difusão processa-se por relocação, por contágio, por via hierárquica ou por saltos. Entre os inúmeros exemplos estão as migrações do passado e do presente, a dispersão da agricultura em geral e em particular de plantas e animais, da cidade em tabuleiro de xadrez, de máquinas, sementes, pragas, capital, informações e ideias. A difusão por contagio, por saltos ou por via hierárquica, cada uma com sua própria espacialidade. 
Sob a égide da globalização, a difusão está sob o controle da grande corporação, gerando redes geográficas constituídas por redes controladas direta ou indiretamente por poderosas "holdings" localizadas em importantes centros de gestão do território.

A dispersão a partir de criações 'in sito' traduz-se em inúmeras pequenas concentrações de atitudes ou em ocorrência efetivamente isolada. Tradicionalmente, elas se manifestam como 'lojas de esquina', constituídas por armazém, açougue, padaria, farmácia, quitanda e bar, frutos de criações de pessoas das redondezas, pessoas que estão integradas na vida de uma seção do bairro. Estas 'lojas de esquina' resultam da demanda de bens e serviços permitindo a dispersão a partir de criações locais. Os 'centros de bairro', mais complexos e menos numerosos, resultam, em essência, do mesmo processo. Ambos, no entanto, estão desaparecendo graças à concentração das atividades por meio da criação e difusão de supermercados, hipermercados e, em outra escala, dos shopping centers. Dispersão e concentração estão presentes na organização espacial da sociedade. Constituem na verdade, temas relevantes e para a investigação geográfica.

\section{Algumas relações entre processos e formas}

Os processos espaciais se efetivam por meio de formas espaciais. No entanto, as relações entre processo e forma são complexas, não sendo possível conceber que estas relações sejam diretas e categoricamente determinadas. A complexidade das relações traduz-se em alguns tipos envolvendo convergência e divergência, refuncionalização, intercausalidade e o papel da escala espacial. Vejamos brevemente cada um dos tipos indicados.

As relações envolvendo convergência verificam-se quando processos distintos convergem para formas funcionalmente semelhantes ou caracterizadas pelo mesmo arranjo espacial. Assim, o processo de produção, 'beneficiamento', industrialização e comercialização do leite e seus derivados pode ser conduzido no âmbito de estruturas econômicas muito distintas, mas os resultados, isto é, as redes, como seus nós e fluxos, podem ser semelhantes tanto do ponto de vista funcional como locacional. Esta convergência se verifica em razão de limites funcionais e locacionais, que impõe padrões técnicos e espaciais. Contudo, não desautoriza que processos distintos gerem formas distintas.

A divergência, por outro lado, significa que um mesmo processo pode gerar formas distintas. Esta divergência parece ser mais freqüente que a convergência. Um exemplo de divergência aparece ao se constatar que o processo de industrialização manifesta-se diferentemente em diversos locais. Assim, uma mineração de ferro, uma mina de calcário ou uma usina siderúrgica podem ser criadas em três locais distintos, enquanto em um quarto criam-se indústrias mecânicas. A escala de produção, a diferenciação dos lugares no que diz respeito aos recursos naturais, acessibilidade e mercados, podem gerar formas espaciais distintas em lugares diversos, porém integradas economicamente. Ressalta-se que na divergência entre processos e formas há ainda que se considerar o papel das elites locais e da tradição de uma força de trabalho qualificada para certas atividades. As relações envolvendo divergência são muito importantes na diferenciação do espaço, construindo em parte a divisão territorial do trabalho entre regiões e centros urbanos. 
A refuncionalização traduz-se na existência de formas espaciais criadas no passado e exercendo funções no presente. É o resultado de processos pretéritos que não mais atuam sobre as formas espaciais por eles criadas. Estas passam a realizar funções do presente, sendo assim, refuncionalizadas. Deste modo o passado inscreve-se em outra temporalidade por meio de formas espaciais de tempo pretéritos.

A refuncionalização é possível em razão da flexibilidade funcional de certas formas, que permitem readaptações funcionais relativamente rápidas e pouco custosas. Pode-se falar em valor funcional, uma variante do valor de uso das formas. A refuncionalização, por outro lado, pode ser o resultado do valor simbólico atribuído a uma forma espacial herdeira do passado, valor inventado ou não, vinculado à estética, aos fatos políticos, ao peso das atividades econômicas que foram realizadas no passado ou a um personagem do passado a ser celebrado no presente e que ali residia.

Valor econômico e valor simbólico sustentam a refuncionalização, presente em toda a parte. A organização espacial do presente está impregnada de passado. Os exemplos são numerosos tanto na escala da rede urbana como na do espaço intraurbano. Cidades tombadas como patrimônio histórico foram refuncionalizadas, denominadas "cidades históricas", assim como cidades com outras funções. Nestes casos, o turismo torna-se a função principal destes centros. Na escala do espaço intraurbano, uma rua, uma praça ou um bairro podem ser refuncionalizados, a exemplo de zonas periféricas do centro que foram "revitalizadas". Na escala dos prédios, os exemplos são numerosos e a refuncionalização não exibe um padrão regular de transformações. Assim, um cinema pode ser refuncionalizado em agência bancária, supermercado ou templo religioso; enquanto uma estação ferroviária em museu, shopping center ou centro cultural; uma fábrica em shopping center. Este último, por outro lado, pode surgir a partir de uma antiga prisão, enquanto um prédio público ou fábrica podem, por meio de ocupações, transformar-se, mesmo que provisoriamente, em habitações populares. Como resultado, a paisagem urbana torna-se híbrida, com formas derivadas de complexos processos de refuncionalizações.

As relações entre processo e forma não são necessariamente monodirecionais, o processo gerando a forma. Verifica-se uma intercausalidade na qual a forma deixa de ser apenas o efeito tornando-se também causa. Há, assim, uma relação dialética entre processo e forma. Cada um é simultaneamente marca e matriz, conforme aponta Berque. A fixidez e duração das formas espaciais permitem esta possibilidade, assim como a escala de operação da atividade gerada por um dado processo. Um distrito industrial a partir de uma fábrica constitui um exemplo, assim como as áreas industriais desenvolvidas a partir de pequenas indústrias que criam demandas que atraem outras indústrias funcionalmente localizadas a montante ou a jusante do conjunto de unidades industriais do mesmo setor. Nestes termos as economias externas de aglomeração podem ser vistas como resultantes da intercausalidade.

As relações entre processo e forma, finalmente, não estão isentas das implicações que a escala espacial exerce sobre a ação humana. Escala global, nacional, regional e local, por exemplo, implicam em práticas e impactos distintos. Neste sentido, as reflexões teóricas devem ser pensadas escalarmente: em outras palavras, o que é valido para cada escala, ainda que haja uma necessária interdependência entre elas.

Processos globais podem manifestar-se de modo distinto de usas manifestações regionais 
ou locais, tal como foi discutido ao se abordar as relações entre processo e forma caracterizadas pela divergência. É assim que uma rede regional de filiais de uma corporação é submetida a práticas de gestão distintas daquela de uma singular unidade da mesma rede. E é neste sentido que se deve estar atento às interpretações sobre a organização do espaço em suas múltiplas manifestações escalares.

\section{As interações espaciais}

As interações espaciais constituem os meios pelos quais as formas espaciais articulam-se entre si, realizando as funções que os processos espaciais lhes atribuíram. Processos, formas e interações espaciais constituem uma unidade, não sendo possível compreender a espacialidade humana sem recurso a essas três dimensões. As interações espaciais, por outro lado, não são apenas meios, mas também reflexos e condição de e para processos e formas espaciais. Estas relações, contudo, são muito complexas e aqui não serão consideradas.

As interações espaciais estão presentes na História e na Geografia da espacialidade humana, denotando as condições diferenciadas em que a existência e reprodução humana ocorriam e ocorrem. Há uma forte relação entre o tipo de sociedade e a natureza das interações espaciais, distinguindo-se, por exemplo, as interações realizadas pelas hordas primitivas, comunidades de camponeses, sociedade feudal, colonial e capitalista, entre outras. A partir da Revolução Industrial e da ascensão do capitalismo, as interações espaciais tornaram-se mais complexas e intensas. $\mathrm{O}$ estágio atual é um capítulo em uma longa historia das interações espaciais, quer dizer da espacialidade humana, envolvendo o permanente esforço de superação do espaço pelo tempo.

As interações espaciais variam no espaço e no tempo, onde estão inscritas. No espaço, a distância, a intensidade e a direção desempenham importante papel de diferenciação. Custos distintos de transferência, quantidade e qualidade de produtores e consumidores diferenciadamente distribuídos interferem no resultado; distancia percorrida, intensidade e direção das interações espaciais são elementos que contribuem para a compreensão da espacialidade humana. No que diz respeito ao tempo, as interações espaciais variam segundo a duração, a velocidade, a frequência, o ritmo e o período de ocorrência. Interações longas ou curtas, lentas, rápidas ou instantâneas, diárias, semanais ou mensais, separadas por um maior ou menor lapso de tempo e ocorrendo em períodos próprios, como na safra, férias ou no tempo sagrado, revelam possíveis variações que aparecem de modo combinado. O mapa do mundo é recoberto por inúmeros fluxos, distintos qualitativa e quantitativamente, revelando a espacialidade humana desigual, reforçando a desigualdade das formas espaciais.

As interações espaciais criam também sua própria forma espacial. A rede geográfica é uma particularidade da rede em geral, objeto da topologia, e se manifesta em redes elétricas, fluviais, de parentesco e as denominadas redes sociais. A rede geográfica distingue-se das demais por apresentar dois atributos: ser social e exibir a sua própria espacialidade, efetivamente reconhecida como distintiva dos outros tipos de redes que, embora dotadas de espacialidade, não são reconhecidas e analisadas nesta perspectiva. 
Redes das grandes corporações, multifuncionais e multilocalizadas, redes políticoadministrativas, tanto na esfera do Estado como das religiões, redes ferroviárias, uma bacia leiteira e a rede urbana, espécie de síntese das redes geográficas, recobrem o mapa da espacialidade humana. Como outras formas espaciais, a rede geográfica é simultaneamente reflexo, meio e condição social e, por isso, importante objeto de investigação.

Há uma tipologia de redes geográficas que denota as complexas relações entre processo e forma. Entre os diversos tipos de redes consideremos apenas quatro, a saber: rede solar, christalleriana, dendrítica e de múltiplos circuitos. Estes tipos não são cronologicamente ordenados, não havendo uma sucessão de um tipo a outro, mas cada um tem sua própria funcionalidade no âmbito do sistema social em que está inscrito.

As redes do tipo solar caracterizam-se pela magnitude e força centralizadora de seu foco principal, seja ele uma cidade, empresa ou instituição: a metáfora do sol é muito pertinente. Neste tipo de rede, os subordinados são muito pequenos em face ao foco principal, com o qual tendem a manter interações espaciais exclusivas ou quase. Relações entre os focos pequenos, comparáveis entre si, são inexpressivas e implicam na necessidade de utilização do foco principal para acesso aos demais.

A rede do tipo christalleriano recebeu este nome em homenagem a Walter Christaller, autor da teoria dos lugares centrais, uma proposição a respeito da rede urbana. Diferentemente da rede solar, esta apresenta uma hierarquia entre a cidade principal, centros intermediários e pequenos centros. No entanto, as interações seguem uma dada direção, de um pequeno centro para um centro intermediário e deste para a cidade principal. Não há interações entre centros de mesmo nível hierárquico. Trata-se de uma rede solar mais complexa, cujo foco principal não tem a mesma magnitude e força daquela da rede solar. Este tipo de rede é muito significativa para regiões caracterizadas pela economia agrária tradicional ou moderna, a exemplo da maior parte do território brasileiro.

As redes do tipo dendrítico, por sua vez, tem seu nome associado à rede fluvial, que, de fato, condiciona a localização dos centros urbanos e das interações espaciais. O centro principal localiza-se excentricamente, junto ao estuário de um rio grande. Trata-se, via de regra, da cidade mais antiga, ponto de entrada e conquista de um território a ser conquistado e ponto de entrada e saída dos produtos de sua hinterlândia. Há uma hierarquia de centros que se localizam nas confluências de rios menores e hierarquia que decai da jusante para a montante. A forma da rede do tipo dendrítico denota a sua história. De natureza colonial, este tipo de rede é ou foi corrente nos continentes americano e africano. No Brasil, a cidade de Belém constitui um exemplo conhecido de cidade que até 1970, aproximadamente, comandava a rede urbana do tipo dendrítico da Amazônia.

A rede de múltiplos circuitos, diferente das demais, é típica das áreas desenvolvidas. Caracteriza-se por uma relativa distribuição do poder econômico e político entre os centros urbanos e por múltiplas vias pelas quais as interações espaciais se realizam por múltiplos circuitos. A diferenciação entre os centros urbanos se faz mais por meio da hierarquia entre elas. Complementaridade e interdependência são mais importantes que a hierarquização e subordinação entre centros que dispõem, via de regra, de significativas atividades industriais.

A ocorrência deste tipo de rede denota um maior nível de desenvolvimento econômico e so- 
cial, sendo indicador deste nível, a exemplo do que ocorre em certas áreas do sudeste e sul do Brasil, país cuja diversidade e dinâmica social e econômica sugerem pesquisas sobre redes geográficas.

\section{Considerações finais}

Este breve ensaio procurou ressaltar três pontos fundamentais para análise geográfica: processo, formas e interações espaciais. Profundamente associados entre si, eles foram brevemente discutidos de maneira articulada. No entanto, é possível derivar temas para pesquisa, alguns dos quais foram abordados no passado pelos geógrafos brasileiros, tendo sido posteriormente negligenciados. A análise da distribuição espacial da produção é um destes temas, assim como a análise de diversas interações espaciais. Banco de dados geográficos envolvendo a espacialidade das formas e interações espaciais podem ser úteis para o conhecimento continuo e sistemático do Brasil. Entre outras coisas, é necessária uma verdadeira imaginação geográfica capaz de descobrir a espacialidade humana em suas inúmeras manifestações. 